Article

\title{
Seeing GMOs from a Systems Perspective: The Need for Comparative Cartographies of Agri/Cultures for Sustainability Assessment
}

\section{Amaranta Herrero ${ }^{1, *}$, Fern Wickson ${ }^{1, \dagger}$ and Rosa Binimelis ${ }^{1,2, \dagger}$}

1 GenØk Centre for Biosafety, Forskningsparken, PB 6418, 9294 Tromsø, Norway; E-Mails: fern.wickson@genok.no (F.W.); rosa.binimelis@uvic.cat (R.B.)

2 Agroecology and Food Systems, University of Vic-Central University of Catalonia, c/de la Laura, 13, 08500 Vic, Spain

$\dagger$ These authors contributed equally to this work.

* Author to whom correspondence should be addressed; E-Mail: amaranta.herrero@genok.no; Tel.: +47-9805-7997; Fax: +47-7764-6100.

Academic Editor: Marc A. Rosen

Received: 24 July 2015 / Accepted: 10 August 2015 / Published: 20 August 2015

\begin{abstract}
Over the past twenty years, agricultural biotechnologies have generated chronically unresolved political controversies. The standard tool of risk assessment has proven to be highly limited in its ability to address the panoply of concerns that exist about these hybrid techno/organisms. It has also failed to account for both the conceptual and material networks of relations agricultural biotechnologies require, create and/or perform. This paper takes as a starting point that agricultural biotechnologies cannot be usefully assessed as isolated technological entities but need to be evaluated within the context of the broader socio-ecological system that they embody and engender. The paper then explores, compares and contrasts some of the methodological tools available for advancing this systems-based perspective. The article concludes by outlining a new synthesis approach of comparative cartographies of agri/cultures generated through multi-sited ethnographic case-studies, which is proposed as a way to generate system maps and enable the comparison of genetically modified (GM) food with both conventional and alternative agri-food networks for sustainability assessment. The paper aims to make a unique theoretical and methodological contribution by advancing a systems-based approach to conceptualising and assessing genetically modified organisms (GMOs) and proposing a synthesised methodology for mapping networks of relations across different agri/cultures.
\end{abstract}


Keywords: GMOs; biotechnology; agrifood systems; social cartographies; follow the thing; food networks; multi-sited ethnography; sustainability; socio-ecological systems

\section{Introduction}

Over the past twenty years, modern agricultural biotechnologies have been the subject of chronically unresolved political controversies worldwide. While approaches to governance have largely been restricted to regulation through a technical assessment of risks to human health and the environment, resistance to the commercialisation of genetically modified organisms (GMOs) stems from a wide spectrum of concerns, covering issues well beyond the scope of risk assessment [1-4]. These concerns refer, for example, to (a) the socio-economic impacts of GMOs [5-7]; (b) the loss of freedom of choice for non-GM producers and consumers [8-11]; (c) the increasing concentration of power and capital in the hands of ever fewer social actors [12]; (d) the widespread implementation of patents and intellectual property rights to control the development and distribution of varieties [13-18]; (e) the failure to account for the significance of scientific uncertainties, paradigms and values in the development of knowledge [19-23]; (f) the domineering or hubristic relationship between humans and nature that GMOs perpetuate [24,25]; and (g) competing narratives of development and diverging visions for the role of the bioeconomy and the future of agriculture [26-34].

Researchers have typically conceived and assessed GMOs as neutral, autonomous and individualised technological objects, ignoring the socio-economic and ecological relations these technologies require, create, and/or perform [20,35-38]. In fact, as any technology, GMOs do not exist in a vacuum but operate as socio-technical and socio-ecological systems [39,40]. They inevitably affect and are affected by the networks of relations in which they both circulate, and generate. As hybrid bio/socio/techno objects, they are shaped by the interests, values, goals and visions that arise with their contexts of development and deployment [36]. At the same time though, they also shape the discourses, practices, knowledge, skills, meanings, problems and purposes of the human and non-human actants they emerge into being with [41]. Narrowing regulatory consideration to an assessment of empirically demonstrable risks to human health and safety of biotechnologies as isolated (and isolatable) objects therefore fails to recognise, account for and consider these complex networks of interrelation and co-construction.

Several scholars $[7,32,42,43]$ as well as an increasing number of governments, international organisations and treaties [44-47] have noted the importance of incorporating socio-economic aspects in the assessment of GMOs and for this, the urgent need for grounded empirical research. Furthermore, it has been proposed that such empirical work should take into account the "in-context-trajectory" of modern biotechnologies [35]. Assessing agricultural biotechnologies not as isolated entities but rather as a network of relations, would require an ability to map complex systems of interaction between multiple actants and asking questions about the processes, materials, social institutions, policies, economic forces, and co-technologies contributing to a biotechnological becoming. Furthermore, it would also require an ability to unearth and analyse the worldviews, discourses, paradigms, and motivations of the multiple stakeholders acting and being enacted within that system (e.g., farmers, 
scientists, biotechnological companies, regulators, retailers, civil society groups, consumers, to name but a few).

The specific context for our interest in advancing such a systems-based approach is The Agri/Cultures Project (www.agriculturesproject.org) funded by the Norwegian Research Council to help operationalise the unique requirements of the Norwegian Gene Technology Act. This Act requires that GMOs are assessed not only for their risks but also for their social utility, ethical acceptability and contribution to sustainable development. While this requirement represents a laudable intention and aim; at present, the ability to operationalise these unique features of the Act is severely inhibited by a distinct lack of concrete methods both for performing this type of assessment and developing the necessary or desired empirical knowledge to inform it. The problem of operationalising Norway's unique GMO assessment criteria has broader relevance and significance as the push to extend regulatory evaluation beyond standard risk regulation spreads internationally. For example, the relevance of socio-economic and cultural factors for assessing GMOs was recently given significant emphasis as the European Parliament agreed to pass new legislation allowing member states to restrict the cultivation of GMOs on their own territory using grounds that include environmental or agricultural policy objectives, socio-economic impacts, and avoiding the unintended presence of GMOs in other products. Since this legislation has only entered into force recently (spring 2015), it is not yet clear how these factors will be used by European Union (EU) member states [48]. Furthermore, the European Food Safety Authority recently adapted its guidelines for environmental risk assessment of insect resistant GM plants to include the receiving environment and its "management system" [49], although exactly how to incorporate this element in practice also remains open to interpretation. Additionally, signatories to the international Cartagena Protocol are currently discussing how to include socio-economic considerations in the biosafety assessment of living modified organisms [50-53], although again, specific criteria or methods for this have yet to be agreed [54]. Challengingly, as the demand for assessing biotechnologies within a broader framework of agricultural practices increases, the currently globalised and highly distributed nature of modern food systems actually decreases the ability of both publics and policymakers to understand and assess the complex networks involved. There is therefore an increasingly urgent need to develop new concepts to understand the broader range of relational networks involved in modern agricultural and food production systems and novel methods to capture, communicate and assess them.

However, even if we can agree that such an extended systems-based approach is important, the question remains - how might the work be done in practice? What would it look like to see and assess GMOs from a systems-based perspective? How could such a complex socio-ecological network of both conceptual and material relations be mapped? What methods are available for this work and what are their strengths and weaknesses for the task being proposed? Furthermore, how could such cartographies of complex systems be used in assessment for the purposes of regulation?

In the text that follows, we review some of the available work from across different disciplines and traditions that may be useful for advancing such an approach and evaluate their relevance and comprehensiveness for the task at hand. This specifically includes work within the fields of agri-food research, actor network theory, ethnographic following and social cartographies. Following this review, we propose a set of methodological guidelines for creating comparative cartographies of agri/cultures for the purposes of advancing a systems-based approach to our understanding and assessment of GMOs. We use the term agri/cultures here to specifically emphasise the important socio-cultural aspects of 
agricultural systems and the way in which they are entangled with the biological-material dimensions. We also use the term in the plural to draw specific attention to the existence of different cultures of agriculture (i.e., different beliefs and behaviours that come together to characterize a way of life and are passed down through generations) such as those embodied in GM, conventional and alternative approaches, and which need to be mapped and compared if we are perform an assessment of their sustainability and acceptability.

\section{The Development of Agri-Food Research}

Agri-food research is a vast umbrella term that can be used to describe a body of work over the last three decades that has aimed to consider the place of food in continuous systems of research and experimentation, production, distribution, exchange, consumption and disposal. In combining the terms agriculture and food, agri-food can be viewed as an expression covering an interest in both agricultural systems and food systems more broadly. For example, an interest in agricultural systems can cover the cultivation of non-food crops such as cotton, or potential food crops that are actually used for industrial purposes, such as maize for bioethanol production. Likewise, an interest in food systems can include food for non-human consumers (i.e., feed) and need not focus only on terrestrial agricultural production but can also be directed towards aquaculture systems or wild harvesting. While agri-food research has arguably traditionally focused on terrestrial agricultural systems directed towards food production, understanding of the term need not be limited in this way. Indeed for those interested in biotechnologies, a focus on both agricultural and food systems broadly conceived is important and can be usefully captured using the short-hand phrase of agri-food systems.

In the first wave of agri-food research, the field was dominated by a focus and examined these using sociology and a political economy approach, with scholars being primarily concerned with describing the macro-structural (including economic) dimensions that give shape to the dominant model of industrialised, monocultural, input intensive, fossil fuel dependent and globalised food production system [55-58]. The so-called theoretical "qualitative turn" promoted by post-structural and post-modernist social theory that spread through many social science fields, also reached agri-food research during the late 1990s. This theoretical shift, together with a number of significant events (such as multiple food scandals and scares, the rise of biotechnology and its controversies, and the emergence of so-called "alternative" food systems) shaped a reconceptualisation of agri-food research. In the wake of these events, its focus expanded beyond the realm of production in order to also include relations emanating from the consumption and distribution of foods [59-61]. This "consumption turn", as Dixon [59] points out, also implied a shift towards more cultural, action-oriented, relational and intersubjective accounts of power. At the same time, more attention was brought to a wider range of actors, including non-humans such as nature or landscape [62,63], which were conceptualised as constituent dynamic elements affecting and being affected by agri-food networks.

Agri-food research has typically divided its object of study into two separate and often antagonistic ideal types, based not only on different agricultural practices and socio-environmental impacts, but also on different values, power relations and even cultural paradigms [64]. These divergent ideal types have been labeled "conventional" and "alternative" agri-food networks. While "conventional" generally refers to production processes seeking to maximise economic utility, efficiency and competitiveness 
within a global industrial food complex (and typically resulting in product standardization and environmental damage), "alternative" is used to refer to food production processes characterised by values of localisation, environmentally-friendly practices and short production and trading chains that include (to varying degrees) embedded information related to the social, environmental, or health dimensions of food production [65]. Although diverse in form, these alternative systems are also often concerned with establishing grounds for new relationships of association [66]. While the labels of "conventional" and "alternative" for these ideal types can be problematized (especially by the way in which smallholder family farms focused on self-sufficient production have historically been the dominant form of agriculture and remain a typical or "conventional" approach to agri-food production from a global context), for the purposes of this review we can use the terms as they are widely adopted in the field.

Most recent agri-food research has typically given enhanced weight to the characterisation of "alternative" food systems. It has been primarily concerned with refining the definitions of alternative agri-food networks and providing contextualised examples of how these are embedded and perform in different places $[67,68]$, as well as outlining patterns of convergence and divergence among these networks [69]. A significant number of scholars [70-82] have, for example, emphasised and examined localism and "short-supply chains" in alternative food networks. Third-party certification schemes of "alternative" food systems have also been a theme $[83,84]$. Additionally, the transformative potential of such networks has been broadly scrutinised through the characterisation of the actors and social movements who display material and discursive strategies to try to reduce food miles and reconnect producers and consumers [68]. Along these lines, some scholars have identified the challenges these movements face in their quest for social change [69] and criticised the limited commitment of many alternative food networks for incorporating criteria of social justice and equity [85].

However, within agri-food research there is now a growing number of scholars giving particular attention to the often-blurred boundaries or "slippage" between the so-called "conventional" and "alternative" food networks. These scholars challenge the idea that the food system can be accurately characterised and captured by these two static ideals (ideals which are often portrayed as competing tensions and come with attached and simplified assumptions of good and bad) [86]. These scholars rather advocate for the existence of a myriad of agri-food projects that try to navigate in permeable arenas. Here scholars have particularly identified processes of "conventionalization" in alternative agri-food networks $[65,83,84,87,88]$. These processes are mainly linked to the rise of certain social practices that sees alternative systems increasingly coming to resemble, in structure and ideology, those of the conventional agri-food system. For example, this can include: (a) a partial dilution of the principles embedded in organic production by the proliferation of "new organic producers" whose primary concern is with the market opportunity of organic production and whose key focus is then on following the mandates of organic labeling; (b) an increased appropriation of organic production by an agribusiness model focused on large-scale production for economic profit and efficiency, which could marginalise pre-existing organic producers; (c) the threat of agro-ecological practices becoming increasingly shallow or compromised due to enhanced price competition in the sector; (d) the reinforcement of conventional channels of commercialisation and trade (e.g., in large supermarkets) rather than a commitment to shorter food circuits that can increase reconnections between producers and consumers; or (e) the corporate cooption of Fair Trade or sustainable farming standards [89]. In fact, the labels of "Civic Food 
Networks" [90] or "Autonomous Food Networks" [91] have been proposed as better ways to capture some of the unique characteristics of grassroot practices found in what has previously been described as "alternative" food networks.

While the permeability between "conventional" and "alternative" agri-food systems is increasingly being acknowledged and accepted within the field, some authors point out the need for grounding this "conventionalization" thesis in specific contexts, i.e., understanding the materialisation of interrelations between the systems and analysing how these processes are actually taking place [92,93]. Despite this call for grounded empirical work on the phenomenon and the widespread acknowledgment of the permeability of the "conventional"-"alternative" dichotomy, the distinction between these two ideal types persists in the academic literature on agri-food networks.

Despite extensive and growing coverage of the array of practices and contexts associated with alternative food networks, very little has arguably been said within agri-food research concerning the nuances and diversity within "conventional" agri-food networks and especially, the role and significance of the rise of GMOs as a network sui generis. Conceptually it is often argued that GM agriculture represents a renewed or extended version of the dominant agro-industrial paradigm [94]. However, work has not been done to systematically document and compare networks of socio-ecological relations across $\mathrm{GM}$, conventional and alternative agri-food systems. One recent and significant exception is the work done by Freyer and Bingen [95]. Using Beus and Dunlap's [64] paradigmatic comparison between agricultural systems, the authors analyse the potential convergence and divergence dynamics between four agri-food systems (organic-traditional; organic-conventional; integrated pest management-conventional, and GM-farming). Despite this example, which is grounded on the different agricultural management strategies from the different systems, the singularities and idiosyncrasies of the material manifestation of GM agri-food relational networks have not been thoroughly studied empirically, and particularly not within the field of agri-food research.

One of the particularly interesting contrasts for considering GMOs within an agri-food perspective is that, although agri-food research has often structured its work around a divide and comparison of "conventional" and "alternative" food systems, the regulation of GMOs typically involves only a comparison between GMO and conventional agricultural systems. Given the current reliance on risk assessment as a regulatory tool, the idea is that if GMOs are seen to pose no greater risks to human health or the environment than are accepted within conventional agri-food systems, then the risks of GMOs should also be deemed acceptable. If it is true that GM agriculture merely renews or sits within the broader structures, ideals and practices of a conventional approach anyway, the comparison could be argued to reveal very little and again, work against the consideration of the full range of concerns and objections to GMOs outlined above. Indeed the strongest critics of GMOs are often supporters of "alternative" agri-food systems and therefore comparing GM only with conventional models fails to adequately capture or explain the issues seen to be at stake. It has also been argued that this single axis of comparison with conventional approaches represents a backward rather than a forward looking approach, encouraging development that is no worse than the unsustainable systems we already have, rather than encouraging development towards the systems we actually see as socio-ecologically desirable for the future [23]. 


\section{Actor-Network Theory and Agri-Food Research}

Actor-Network theory (ANT), as developed within the field of science and technology studies (STS), has been presented as a particularly promising theoretical and methodological tool to capture the complexities of the relational networks in agri-food systems [62,96-101]. A first advantage of using ANT in agri-food research is that it can be an integrative tool to bridge the analysis of macro perspectives (such as political economy accounts focusing on the analysis of structural elements and dynamics), with micro perspectives (focused on the interactions and social practices of the actors involved). ANT's relational focus also broadens the spectrum of actors that can be considered as part of agri-food networks by its characteristic extension of the notion of (human) actors to (nonhuman biological and technological) actants as significant entities with agency. The relational approach also offers a framework to understand the extension and co-constitution of agri-food networks across scales and localities [97]. This opens for not only the importance of paying more attention to what happens beyond the farm gate [100] and understanding how "things become food" [102], but also for expanding the spectrum of analysis from both ends to include the black boxes found before the farm gate (e.g., in agricultural R\&D processes) and also beyond consumption (e.g., the material degradation and its management embedded in each of stage from production-consumption). Such an approach therefore encourages the identification and description of processes, practices and discourses of actors involved in a range of stages from $R \& D$, production, distribution, exchange, consumption and disposal of food.

As stated above, a characteristic aspect of ANT is that it not only takes into account human agency, but also extends it to the realm of non-human entities. Thus, nature, technological artifacts, knowledge and policies can all be considered actants as they have the capacity for acting and being acted upon. Within ANT, agency is conceptualised as a relational effect of heterogeneous networks and therefore refers to the capacity for action of both human and non-human entities [103-105]. A general emphasis within ANT is on the hybrid co-productions of nature-culture within actor-networks. When studying agri-food networks, this approach can offer new insight and inspiration as both agri/culture as a general practice and key elements of it (such as domesticated crops) can be understood as historically evolving nature-culture co-productions [106,107]. Furthermore, GMOs clearly condense the materialisation of these hybrid entities, bringing the fusion of the biological with the social and technological to a qualitative distinct level. By articulating new concepts that allow for both defining these hybrid entities and transcending the persistent dualism between nature and culture, ANT enables a fuller range of actants with agency in agri-food systems to be identified and studied for their influence and role.

Despite the initial eagerness in which ANT was presented and advocated for within agri-food studies, there remains a surprising lack of work either articulating details of a specific method, or presenting empirical explorations or applications of the theory through method in agri-food research. Busch and Juska [97] offer one of the few examples in which ANT is explicitly applied to the study of agri-food systems, using a case study of the Canadian rapeseed sub-sector. The authors show how the transformation of this sub-sector from its initial industrial purposes to edible oil took place in Canada. They extended a political economy approach by using ANT to broaden the venues of action and link several institutions involved in the shared-construction of rapeseed as a mass-consumed commodity in Canadian kitchens. As some authors also note [62,100], however, in the end, the network they describe includes actors from different sectors but remains anchored at the institutional level, heavily influenced 
by the macro-structural analysis of their political economy roots. Additionally, in methodological terms, it remains unclear what criteria guided the decisions they took in order to filter the actors considered for the network and create their framework of reference.

In another example, Holloway et al. [68] developed a methodological framework to study production-consumption networks and applied ANT to the study of some examples that constitute part of the alternative food network in the UK. They used two case studies to heuristically analyse some of the main dimensions of these agri-food networks. The dimensions of interest were: sites of production; production methods; supply chains-arena of exchange; producer-consumer interactions; motivations; constitution of individual or collective identities. Their research highlights relevant elements characterising their selected agri-food networks, successfully shows the relational character of power, and reinforces the idea of diversity within the alternative food systems. However, it seems to ignore structural elements and certain actants within the system (such as legislation, institutions, etc.) that can be seen to strongly affect and condition the rest of the network and also the role of non-human actants. By adopting a focus on specific aspects of the production-consumption chain for detailed exploration, the work also does not provide an impression or overview of the agri-food system as a whole.

This means that, although ANT seems to offer potential value for agri-food research and seems to offer interesting concepts, it remains vague and underdeveloped in terms of methods that can be applied.

\section{Social Cartographies, Ethnographic Following and ANT}

Within its home base of STS, ANT has inspired the development of the "cartography of controversies", a method to study social debates in which it is common to find a relevant sociotechnical dimension. It is generally presented as a simplified version of ANT practice and as a ready-to-use toolkit [108]. Despite its claims, however, this approach also provides only vague and suggestive methodological guidance. In the most systematic attempt to describe how to put into practice the cartography of controversies, Venturini [108] advises going into the fieldwork to scrutinise reality with minimal assumptions or methodological protocols. The guidance effectively being offered is therefore something like: "go, see, and let yourself be surprised". While this is a useful reminder to be open and receptive as a researcher, STS scholarship more generally has advocated the importance of recognising that researchers do not enter fieldwork or experimentation empty of ideas and values and arguably, that attempting to do so can blind the researchers to the beliefs and frames that structure and shape their sight. If we adopt the position that researchers are not a white canvas alienated from the reality to be studied but rather observe, describe and analyse the world from somewhere and contribute to its co-construction, the guidance from ANT for the development of cartographies lacks practical value.

While Venturini [108] does not present a systematic method to put into practice the generation of a cartography of controversy, some important principles for the work are provided, such as (1) using a promiscuity of available methods at hand; (2) mapping as many perspectives as possible and (3) respecting all actor's point of views. Additionally, during the observation period of the social controversy, this author also suggests five progressive lenses that can nurture the data gathering during this phase of the research. They would imply approaching the social phenomena through escalating layers going (1) from statements to literature; (2) from literature to actants; (3) from actants to networks; 
(4) from networks to cosmoses; and (5) from cosmoses to cosmopolitics. This notion of studying networks through the identification and articulation of escalating layers can be useful for mapping agrifood systems, although the content of the layers may differ in this context.

Although some of the cartographies of GMO controversies found in the literature report on specific episodes regarding the development of these technologies [109,110], their contributions arguably remain limited for our purposes since they have not taken the trajectory of GMOs through the food chain as a research compass nor necessarily the relational elements of the agri-food network system in which they circulate. Another area of research that has arguably developed a fuller account of a methodological approach that is in line with ANT is that of "follow the thing" forms of multi-sited ethnography. This approach also offers potential value for the task of seeing and assessing GMOs within their broader networks of relations. Marcus [111] argued that some social phenomena are constructed by a wide range of actors located in different contexts or places, and that ethnographic methods should be able to adapt to track these dispersed phenomena in which the local meets the global. In order to address this, he developed the concept of "multi-sited ethnography" and distinguished six examples of this approach, namely follow the people, thing, metaphor, plot, story or allegory, life or biography, and conflict. Marcus [111] coined the concept of multi-sited ethnography to refer to the expansion of the traditional intensive single-site location of ethnographic observation and participation to a multiplicity of sites that configure complex social phenomena taking place across scales, times and spaces.

Potentially useful in the spheres of interdisciplinary work, this mobile ethnography is an exercise of mapping through discontinuous contexts sharing connections and associations. Several authors find that multi-sited fieldwork is particularly well suited to study networks [112,113]. Some of the most pertinent criticisms of multi-sited ethnography have, however, been related to the question of depth. Ethnography has been widely recognised by its immersion in localised context and its dense descriptions about these realities. Some authors [114] point out that by doing multi-sited ethnography, the depth becomes lost and with it the purpose of ethnographic work. As Wittel [115] illustrates, however, the debate on whether multi-sited fieldwork can afford the development of a radiographic depth to the study of a network is actually one about nuances of ethnographic complexity. Depth can be differently achieved depending on several factors conditioning the research, such as the number of sites to be studied, the time available to do the fieldwork, the economic resources mobilised or the number of people doing the work. Horst [116] argues that, depending on the phenomena to be studied, fieldwork in one location may be as partial as multi-sited fieldwork, since it actually fails to analyse connectedness and focuses instead on isolation. The author concludes that, even if multi-sited research does not provide a dense description of specific nodes (which can vary depending on the research resources), it would guarantee a dense description of the network as a whole, including its dynamics and the interplay of relations between actants, processes, places, practices, discourses and meanings.

Articulating connections across scales, times and spaces has been approached for various food items through the "follow the thing" approach, with varying degrees of success. For example, the social and spatial stories of food and their global-local connections have been told for the links between Mayan broccoli producers in post-war Guatemala and American consumers [117], Jamaican papaya producers and UK consumers [118] and the relations surrounding the West Indian hot pepper sauce [119]. In most of these cases, despite developing an attractive and intuitive idea, the follow the thing approach currently remains a diverse set of approaches used to paint vignettes rather than providing methodological 
guidance that can enable comparative studies. Perhaps the most distinctive and interesting research of this type though is from Harvey et al. [106], which traces some of the most remarkable episodes that explain the social construction of the tomato in Western society, from the importation of tomatoes by the Spanish in the middle ages through to the invention of the GM tomato. Regarding the methodological aspects of this research, an unconventional cocktail of methods (such as historical research, analysis of statistical data, case studies, observation and interviews), have shaped what the authors have basically described as a method that involves "following their own noses".

\section{Guidelines for the Development of Multi-sited Cartographies of Agri/cultures}

There seems to be significant potential value in both the approach of ethnographic following and the use of ANT for studying agri-food systems and developing cartographies of complex socio-ecological phenomena such as agri/cultures. However, both ANT and ethnographic following lack clear methodological guidelines for their application in practice. While interpretive flexibility of methods can have value for sponsoring creativity, flexibility and context-sensitivity in research approaches, to enable comparative analysis, the development of a common method or shared set of guidelines is crucial. Given our argument that we need to consider GMOs from a systems perspective in a way that enables comparative analysis with conventional and alternative agri/culture networks, we therefore offer some methodological guidelines for developing comparative cartographies of agri/cultures. We hope that by offering this set of methodological guidelines, developed through a synthesis of agri-food research, ANT, social cartographies and ethnographic following, we may support the development of a capacity to create comparative cartographies of agri/cultures more generally. We aim to develop guidelines that can be used to create maps of different agri-food systems that can then be used by scientists and stakeholders, policy makers and publics, to better see, understand, compare and assess different cultures of agri/culture and the place of particular technologies within them.

To approach this task, we emphasise the value of developing comparative cartographies of agri/cultures. To do this in our case, we have chosen a kernel of maize as the "thing" to be followed across GM, conventional and alternative agri-food systems in the specific contexts of Spain and South Africa. For us, GM insect resistant Bt maize is the case study crop that the comparative cartographies seek to illuminate. Maize is both a staple crop cultivated by peasants and subsistance farmers in many regions in the world and one of the main agricultural commodity products traded in international markets. Beyond being just a food crop, it is also a key raw material for various industrial products and additives [120]. Bt maize is a paradigmatic case for GMOs, representing both the second most cultivated GM crop globally and the second major GM trait [121]. Bt maize is also the only GM crop produced on a commercial scale in Europe, despite the implementation of controversial national bans on its cultivation by some member states [122,123]. Furthermore, Bt maize is in widespread use across South Africa, including several later generation-stacked trait versions. Spain and South Africa as case contexts also represent a particularly interesting selection for the work since as early adopters of the technology, they arguably represent "gateway nations" for the entry of GMOs into Europe and Africa, respectively. Understanding the journey of a kernel of maize under GM, conventional and alternative agri-food systems across the cultural contexts of Spain and South Africa creates a double comparative axis for our cartographies. 
Following the selection of a grounding object and the system/s of interest for the work, as maps, the comparative cartographies need to create a "travel story" through scales, space and time, using a selection of symbols and characters, and establishing both relations and boundaries. The general approach we propose for this task is that a draft map is first developed through a combination of desk-based research and imaginative projection. The content of this draft map is then discussed (through one-to-one interviews, focus groups or dedicated workshops) with experts and actors with knowledge of different parts of the journey so as further refine the landscape given in the draft. This second stage refinement and reimagining process allows for the generation of a more polished and robust draft map that can then be used to identify the necessary sites for ethnographic work and important interview subjects, as well as to narrow and prioritise the foci of interest if limited resources make this necessary. The map that has emerged to this point is then ready for empirical ethnographic exploration and further refinement through that mode of research. Given our interest in agri/cultures, it is vital that the work not only maps and clarifies the material physicality of the network, but also some of the more conceptual, cultural and philosophical foundations - for example, elucidating worldviews, socio-technical imaginaries and values underlying different agri/cultures.

To give structure to this task of mapping that could, in theory, extend ad infinitum, we propose dividing the task into stages, each of which adds a new layer of depth to the cartography.

(1) Identifying and ordering physical places

As Ruitenberg [124] points out, maps are forms of representation that emphasise spatiality and therefore, the first layer begins with mapping space and place. This stage should seek to first identify the places that the selected grounding object (in our case a kernel of maize) moves through in its travel journey, marking particular nodes of action where concentrated activity takes place. This initial place-based layer to the map is useful to start developing an idea of the scale of the network seeking to be understood. It also, however, serves to help identify the nodes that are better known, documented and understood, and those that seem less clear or well articulated, i.e., the black-boxes. This may be used to guide the research towards particular areas of further focus if necessary.

(2) Noting transitions between places

After mapping the places along the journey, it is important to add mobility and see how the grounding object moves between the physical places or nodes of action. For agri-food systems, this dimension of mobility is particularly relevant as a way to make visible and later take into account the local/global flows characterizing the network. Some of the forms of transport between physical places may be well known and can be documented and included in the draft map on the basis of desk-based research, while others may only emerge during the ethnographic work. For seeking to understand and assess GMO agri-food systems, transport and movement also becomes a particularly significant factor for questions around potential co-existence and contamination.

(3) Articulating actants across places

Drawing on ANT, it is crucial to articulate and add to the draft map the key human and non-human entities acting with agency in these places and the transitions between them. This includes human and non-human stakeholders, i.e., the different technologies, organisms, pieces of legislation and institutions 
that influence the journey of the object of interest. An initial identification of potential key actants during deskwork can facilitate an elaboration of the different profiles of people that it will be important to interview during the ethnographic fieldwork. If first performed as an imaginative articulation (e.g., asking "what actants might we find here?") the exercise also works to sensitise the researcher's eye and mind to non-human entities that act and are enacted in the different places, which can then, in turn, help to broaden and guide the field-based observations.

(4) Plotting processes within places

The fourth dimension of the cartography involves plotting the relevant (economic, technological, cultural, political) processes and situated practices that the grounding object encounters throughout its journey. This stage should collate and iteratively develop an overview of the significant processes involved at different places and specifically include processes where actants interact and influence the form of the next stage of the journey. This can for example include processes influencing research agendas, technology development, product pricing, regulation and trade flows.

(5) Seeing the sub-text

Subtext refers to something that is not explicitly stated but rather which remains implicit and only becomes revealed as a story unfolds. Within this dimension of the cartography creation, it is crucial to prepare relevant themes for attention (depending on the study's specific orientation) and interview scripts that can guide the practice of the fieldwork to allow for drawing out comparative information on the discourses, underlying beliefs, values and worldviews of the systems. It is, for example, important to prepare and structure questions that can reveal the underlying reasons and motivations for why the system is structured as it is, what its underlying foundations are, and how the future is being imagined and pursued.

(6) Iterative development through empirical ethnographic observations and interviews

The final dimension of building the cartography is to enter the field to perform empirical ethnographic observations and interviews so as to iteratively develop the draft map into a robust cartography. At this stage, it is particularly important to document places, processes, actants and subtext in as rich a detail as possible.

Figures 1-3 provide an illustrative example of how the layering of a draft map could develop through to the point of being ready for empirical investigation, using the case of GM maize in Spain. Figure 1 shows the nodes of action or key places that a kernel of maize travels through on its journey. Transport and movement between nodes is then illustrated in Figure 2. Figure 3 fills out some details for the GM case, with a list of example key actants, yellow circles representing moments in which GM contamination can take place, and a traffic icon representing temporal moments in which additional actants (unrelated to specific physical spaces) can intervene in the network and direct the further journey. Figure 3 is therefore an example of an iteratively developed draft that can be used to direct the ethnographic work that will further polish the map and enrich it with empirical content. 


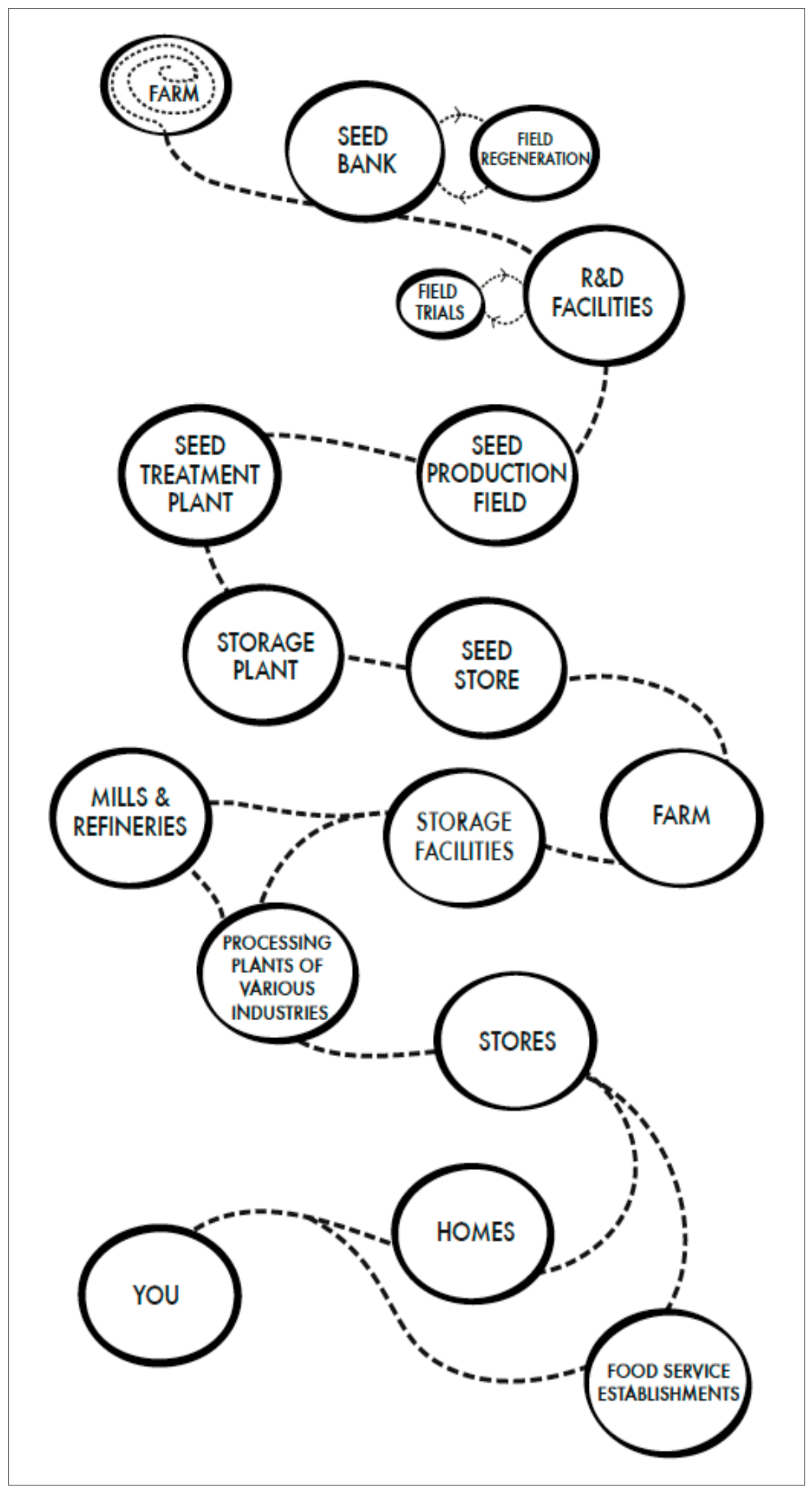

Figure 1. Nodes of action or key places of the GM maize agri-food system in Spain. 


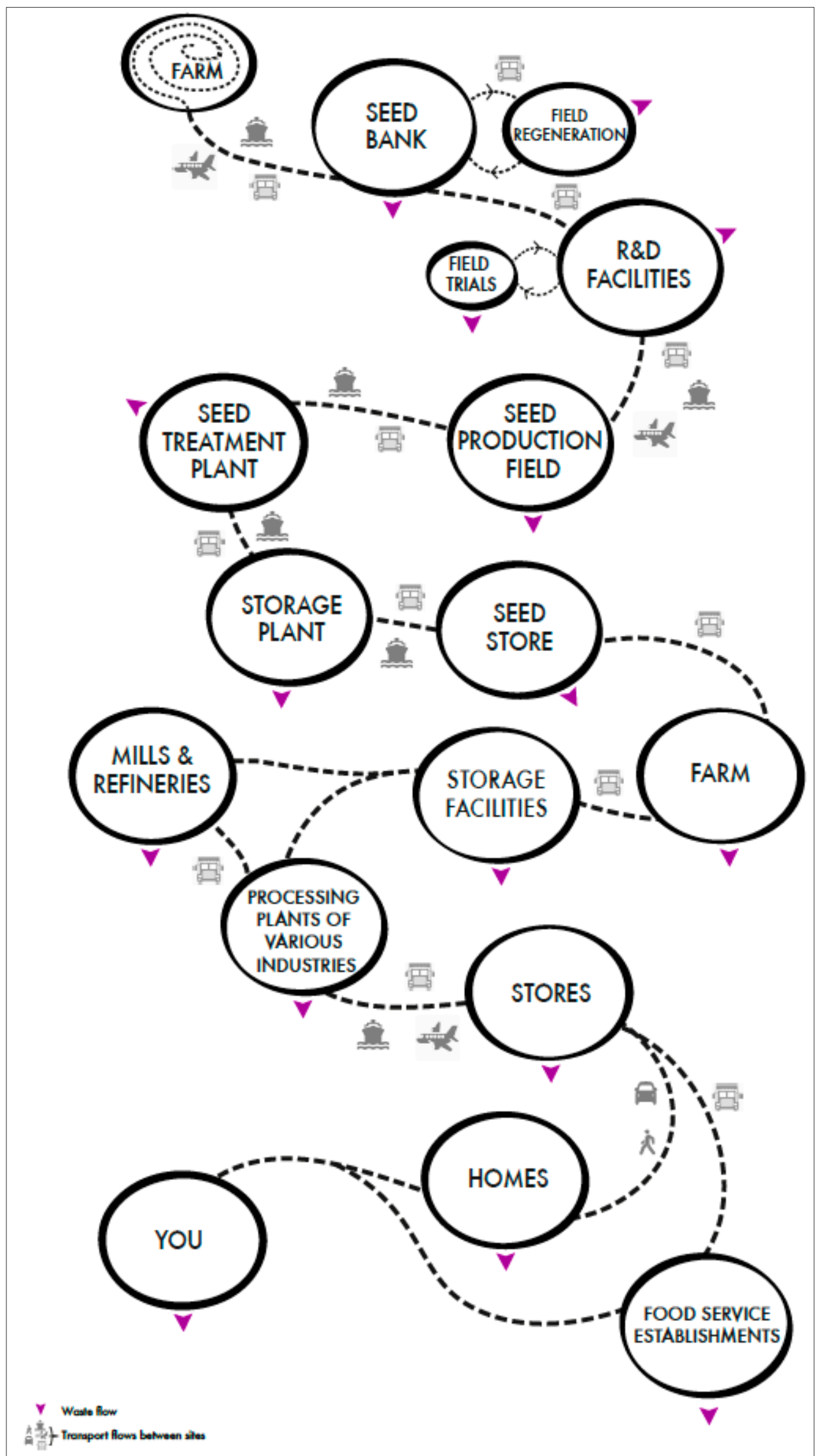

Figure 2. Transport and movements of the GM maize agri-food system in Spain. 


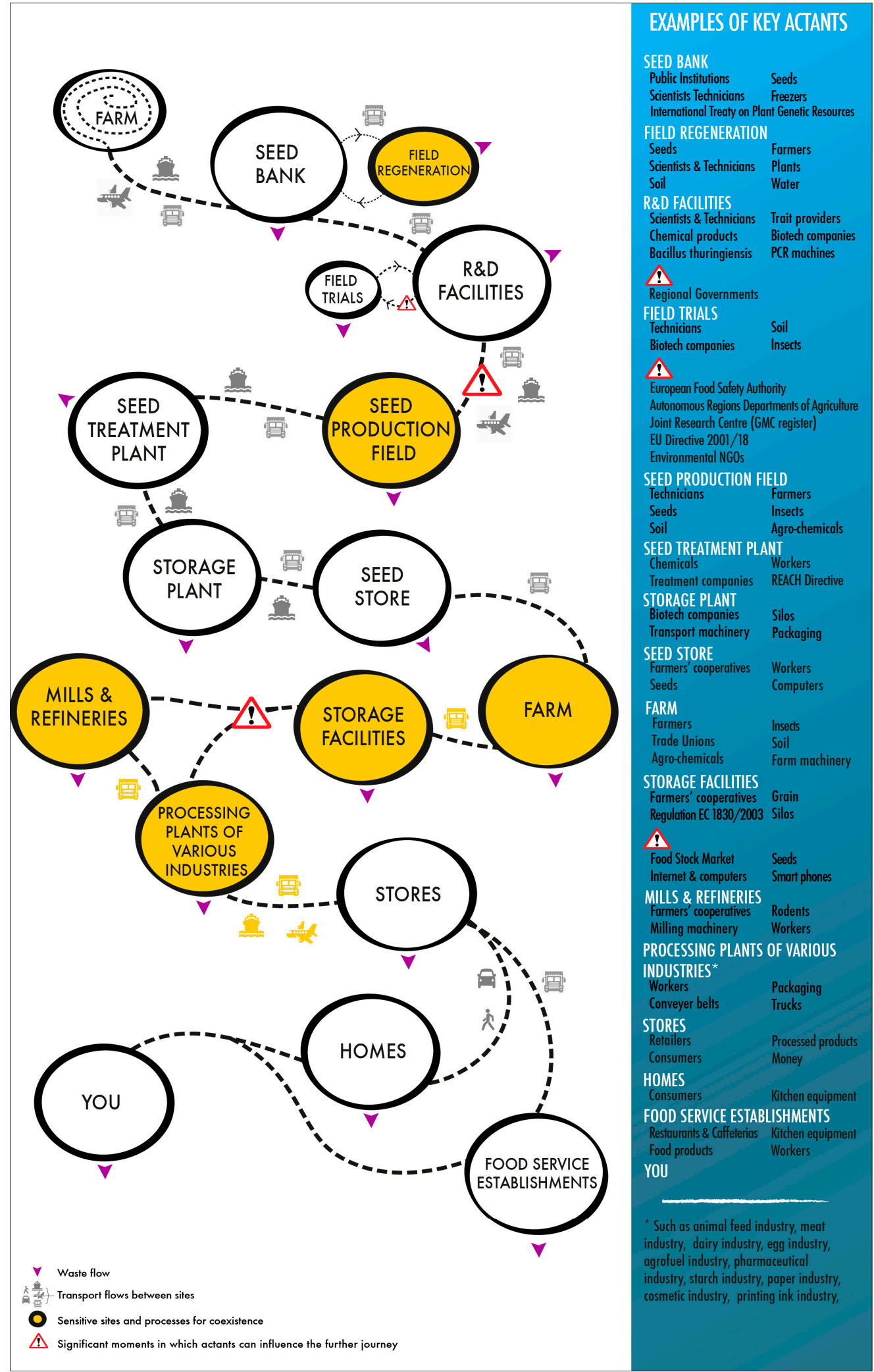

Figure 3. Key actants and sensitive sites for coexistence of the GM maize agri-food system in Spain.

Given our desire to make comparative cartographies that can communicate complexity with a broad audience, how to represent the results is a highly relevant aspect to carefully consider and consciously choose since publishing in standard academic formats and journals will not suffice. The documentary 
genre has been one of the most powerful tools to tell non-fiction stories, fostering reflection about the cultural, political and social aspects of lived human experience. At the same time, today's age of digital culture offers a vast field of possibilities to experiment with emerging forms of representation that can accommodate non-linear, complex and interdependent narratives and within which variable experiences and degrees of interactivity can also be introduced. In fact, several authors have noted the potential synergies between social cartographies and hyperlinked representation [124,125]. Venturini, for example, highlights the growing potential of controversy-websites, that is, websites that track the evolution of ongoing technoscientific public debates and visually display condensed information in a simplified, more understandable way [125]. Merging the documentary genre with the current digital, interactive and networked media, is the emerging field of interactive documentaries (also known as i-doc, web documentary, web doc or multimedia documentary).

Interactive web documentaries can be a particularly interesting way to enhance the representation of the research as different types of information can be connected through hypertext: e.g., video and audio material, photographs, infographics, and text. Moreover, navigating through an interactive webdoc becomes an experience and a co-construction of reality in itself rather than merely its representation [126]. This means that by presenting the cartographies as interactive online experiences (rather than just rich textual descriptions published in academic journals), the different nodes, movements, actants and processes can be documented, communicated and re-enacted in multiple audio and visual forms. This type of experience allows the representation to come closer to the lived experience and fosters participation and immersion for the users; they are able to choose their own journey through the digital material and select the level of depth they want to dig into on any particular site or issue. Such a digitalized approach can also allow them to comment upon and supplement the representations the researchers provide in the cartography, which can then remain visible to other future users.

The use of digital approaches for communicating cartographies of agri/culture need not be limited to a final product. Indeed, in line with emerging ideas about "open science" [127,128] digital forms of communication should be employed all the way through a research project to encourage transparency on the research process and open up the potential for a two-way dialogue with interested stakeholders that can help inform and shape the results. An open science approach proposes not just publishing in open access spaces, but also that researchers engage publics in their work through blogging and the active use of social media, and where possible using these digital tools to lay bare the challenges, uncertainties, assumptions and choices involved in their research process. Using the possibilities enabled by our digital age, such as the creation of i-docs and an active use of blogging and social media, opens for a new approach to communication than can merge text, images, videos and art in interesting new ways and open for a more user directed experience and interactive dialogue between researchers and their audience. We would therefore recommend that the cartographies of agri/cultures that we propose should also experiment with new digital means of communication and the possibilities this enables. Our own experimentation with adopting an open science approach in which we publicly reflect on the research process so as to transparently document important decision points, alternative possible pathways, challenges and choices can be followed at www.agriculturesproject.org.

In offering these guidelines for the creation of comparative cartographies of agri/cultures, we want to recognise that social cartographies do not map truth as such, but rather are provisional representations of the mapmaker's knowledge, interpretation and construction. However, mapping elements of 
comparison contributes to the comprehension of the socio-economic and cultural dimension, provides anchoring points for policymaking and a point of departure for new research [129]. Therefore, although any maps generated will always be provisional and are inevitably presented from a particular perspective, we still believe that the approach can produce knowledge of value for publics and policymakers wrestling with navigating the complex waters of modern agri-food systems.

\section{Conclusions}

In this article, we have argued that a heterodox approach adopting a systems-based perspective on GMOs is required to (a) acknowledge and account for the way in which all technologies are inevitably entangled in complex networks of material and conceptual relations; and (b) to adequately capture, consider and assess the full range of concerns publics have regarding GMOs. We then reviewed different fields of research that may be able to help advance a systems-based approach to agricultural biotechnologies, and suggested that a blend of ANT, multi-sited ethnography and an intuitive "follow our own nose" approach [94] may deliver useful tools to approach the empirical study of GMOs from an agri-food systems perspective. Drawing on and synthesising different approaches, we have proposed agri/culture cartographies capturing and communicating a network of material and conceptual relations as a useful way forward. To be able to see the specificities of certain systems and contexts, and the role of any particular technological innovation within certain systems and contexts, the ability to compare alternatives seems crucial. Such comparison requires some kind of common structure or shared approach. Therefore, while we support creative flexibility in methodological process, to enable work that can serve a comparative purpose, we suggested that it was important to have a clear set of methodological guidelines that could be followed for the creation of agri/culture cartographies. Finally, we suggested that the development and communication of such cartographies will benefit from experimenting with the use of new digital tools and approaches. As a first set of guidelines for the creation of comparative cartographies of agri/cultures, we hope that we can continue to improve their articulation, both through their implementation in our own ongoing work on GM maize, but also through their uptake, experimentation and iteration by others.

\section{Acknowledgments}

The authors would like to acknowledge the useful feedback on an earlier draft provided by Marta Rivera. They would also like to gratefully acknowledge financial support for the work from the Norwegian Research Council (Grant No. 231146). Rosa Binimelis currently holds a Beatriu de Pinós contract funded by the Comissionat per a Universitats i Recerca del Departament d'Innovació, Universitats i Empresa de la Generalitat de Catalunya and the COFUND programme-Marie Curie Actions under the FP7 of the European Communities.

\section{Author Contributions}

Amaranta Herrero led the drafting of the paper, with Rosa Binimelis and Fern Wickson contributing text, supporting references and feedback throughout an iterative process involving several rounds. 
Amaranta Herrero designed the maps with insights from both Fern Wickson and Rosa Binimelis. Fern Wickson performed the final editing. All authors have read and approved the final manuscript.

\section{Conflicts of Interest}

The authors declare no conflict of interest.

\section{References}

1. Kearnes, M.; Grove-White, R.; Macnaghten, P.; Wilsdon, J.; Wynne, B. From bio to nano: Learning lessons from the UK agricultural biotechnology controversy. Sci. Cult. 2006, 15, 291-307.

2. Levidow, L.; Carr, S. GM crops on Trial: Technological Development as a Real-world Experiment. Futures 2007, 39, 408-431.

3. McAfee, K. Beyond techno-science: Transgenic maize in the fight over Mexico's future. Geoforum 2008, 39, 148-160.

4. Wynne, B. Creating Public Alienation: Expert Cultures of Risk and Ethics on GMOs. Sci. Cult. 2001, 10, 445-481.

5. Devos, Y.; Maeseele, P; Reheul, D.; van Speybroeck, L.; de Waele, D. Ethics in the societal debate on genetically modified organisms: A (re)quest for sense and sensibility. J. Agric. Environ. Ethic. 2008, 21, 29-61.

6. Eckerstorfer, M.; Gaugitsch, H. Framing Socio-Economic Assessment in GMO \& Chemicals Regulation; European Environment Agency (EEA): Copenhaguen, Denmark, 2013.

7. Fischer, K.; Ekener-Petersen, E.; Rydhmer, L.; Björnberg, K.E. Social Impacts of GM Crops in Agriculture: A Systematic Literature Review. Sustainability 2015, 7, 8598-8620.

8. Altieri, M. The myth of coexistence: Why transgenic crops are not compatible with agroecologically based systems of production? Bull. Sci. Technol. Soc. 2005, 25, 361-371.

9. Binimelis, R. Coexistence of plants and coexistence of farmers: Is an individual choice possible? J. Agric. Environ. Ethic. 2008, 21, 437-457.

10. Levidow, L.; Boschert, K. Coexistence or contradiction? GM crops versus alternative agricultures in Europe. Geoforum 2008, 39, 174-90.

11. Rodgers, C.P. Coexistence or conflict? A European perspective on GMOs and the problem of liability. Bull. Sci. Technol. Soc. 2007, 27, 233-250.

12. Cáceres, D.M. Accumulation by Dispossession and Socio-Environmental Conflicts Caused by the Expansion of Agribusiness in Argentina. J. Agrar. Chang. 2015, 15, 116-147.

13. McAfee, K. Neoliberalism on the molecular scale. Economic and genetic reductionism in biotechnology battles. Geoforum 2003, 34, 203-219.

14. Scoones, I. Mobilizing against GM crops in India, South Africa and Brazil. J. Agrar. Chang. 2008, 8, 315-344.

15. Stone, G.D. The Anthropology of Genetically Modified Crops. Annu. Rev. Anthropol. 2010, 39, $381-400$.

16. Kinchy, A. Seeds, Science, and Struggle: The Global Politics of Transgenics Crops; MIT Press: Cambridge, MS, USA, 2012. 
17. Kloppenburg, J.K. First the Seed: The Political Economy of Plant Biotechnology; Cambridge University Press: New York, NY, USA, 1988; pp. 1492-2000.

18. Mascarenhas, M.; Busch, L. Seeds of Change: Intellectual Property Rights, Genetically Modified Soybeans and Seed Saving in the United States. Sociol. Ruralis 2006, 46, 122-138.

19. Carr, S.; Levidow, L. Exploring the links between science, risk, uncertainty and ethics in regulatory controversies about genetically modified crops. J. Agr. Environ. Ethic. 2000, 12, 29-39.

20. Devos, Y.; Sanvido, O.; Tait, J.; Rayboul, A. Towards a more open debate about values in decision-making on agricultural biotechnology. Transgenic. Res. 2014, 23, 933-943.

21. Frewer, L.J.; Lassen, J.; Kettlitz, B.; Scholderer, J.; Beekman, V.; Berdalf, K.G. Societal aspects of genetically modified foods. Food Chem. Toxicol. 2004, 42, 1181-1193.

22. Sarewitz, D. How science makes environmental controversies worse. Environ. Sci. Policy 2004, 7, 385-403.

23. Wickson, F. Environmental protection goals, policy and publics in the European regulation of GMOs. Ecol. Econ. 2014, 108, 269-273.

24. Wickson, F. The ontological objection to life technosciences. In Science, Philosophy and Sustainability: The End of the Cartesian Dream; Pereira A.G., Funtowicz, S., Eds.; Routledge: Oxon, UK, 2015; pp. 61-77.

25. Sandler, R. Character and Environment: A Virtue Oriented Approach to Environmental Ethics; Colombia University Press: New York, NY, USA, 2007.

26. Heller, C. From scientific risk to paysan savoir-faire: Peasant Expertise in the French and Global Debate over GM Crops. Sci. Cult. 2002, 11, 5-37.

27. Heller, C. Post-industrial 'quality agricultural discourse': Techniques of governance and resistance in the French debate over GM crops. Soc. Anthropol. 2006, 14, 319-334.

28. Lyson, T.A. Advanced agricultural biotechnologies and sustainable agriculture. Trends Biotechnol. 2002, 20, 193-196.

29. Marsden, T. Agri-food contestations in rural space: GM in its regulatory context. Geoforum 2008 39, 191-203.

30. Rivera-Ferre, M.G. Framing of agri-food research affects the analysis of food security: The critical role of the social sciences. Int. J. Sociol. Agric. Food 2012, 19, 162-175.

31. Rivera-Ferre, M.G.; Ortega-Cerdà, M.; Baumgärtner, J. Rethinking Study and Management of Agricultural Systems for Policy Design. Sustainability 2013, 5, 3858-3875.

32. Arancibia, F. Challenging the bioeconomy: The dynamics of collective action in Argentina. Technol. Soc. 2013, 35, 79-92.

33. Goven, J.; Pavone, V. The bioeconomy as political project: A polanyian analysis. Sci. Technol. Hum. Values 2015, 40, 302-337.

34. Levidow, L.; Birch, K.; Papaioannou, T. Divergent Paradigms of European Agro-Food Innovation the Knowledge-Based Bio-Economy (KBBE) as an R\&D Agenda. Sci. Technol. Hum. Values 2013, 38, 94-125.

35. Pavone, V.; Goven, J.; Guarino, R. From risk assessment to in-context trajectory evaluation - GMOs and their social implications. Environ. Sci. Eur. 2001, 23, 1-13.

36. Van Zwanenberg, P.; Arza, V. Biotechnology and its configurations: GM cotton production on large and small farms in Argentina. Tech. Soc. 2013, 35, 105-117. 
37. Dowd-Uribe, B. Engineering yields and inequality? How institutions and agro-ecology shape Bt cotton outcomes in Burkina Faso. Geoforum 2014, 53, 161-171.

38. Leguizamón, A. Modifying Argentina: GM soy and socio-environmental change. Geoforum 2014, $53,149-160$.

39. McAfee, K. Geographies of risk and difference in crop genetic engineering. Geogr. Rev. 2004, 94, 80-106.

40. McAfee, K. Beyond techno-science: Transgenic maize in the fight over Mexico's future. Geoforum 2008, 39, 148-160.

41. Russell, S.; Williams, R. Social shaping of technology: Frameworks, findings and implications for policy, with glossary of social shaping concepts. In Shaping Technology, Guiding Policy: Concepts, Spaces and Tools; Sørensen, K.H., Williams, R., Eds.; Edward Elgar: Aldershot, UK, 2002; pp. 37-132.

42. Rosendal, G.K.; Myhr, A.I. GMO assessment in Norway: Societal utility and sustainable development. EMBO Rep. 2009, 10, 939-940.

43. Full Picture of GMO Cultivation is Now Shaping up Hearing at the European Parliament on the Socio-economic Dimensions of GMO Cultivation. Available online: http://www. agripressworld.com/start/artikel/457361/en (accessed on 18 October 2011).

44. Falck-Zepeda, J.B. Socio-economic considerations, article 26.1 of the cartagena protocol on biosafety: What are the issues and what is at stake? J. Agribiotechnol. Manag. Econ. 2009, 12, 90-107.

45. Spök, A. Assessing Socio-Economic Impacts of GMOs. Issues to Consider for Policy Development; Lebensministerium/Bundensministerium für Gesundheit: Viena, Austria, 2010.

46. UN Meeting Agrees on Decisions to Advance the Implementation of the International Agreement on the Safe Use of Living Modified Organisms. Available online: http://www.cbd.int/ doc/press/2014/pr-2014-10-03-bscopmop7-en.pdf (accessed on 20 July 2015).

47. Meyer, H. Systemic risks of genetically modified crops: The need for new approaches to risk assessment. Environ. Sci. Eur. 2011, 23, 1-11.

48. Directive (EU) 2015/412 of the European Parliament and of the Council of 11 March 2015 Amending Directive 2001/18/EC as Regards the Possibility for the Member States to Restrict or Prohibit the Cultivation of Genetically Modified Organisms (GMOs) in Their Territory Text with EEA Relevance. Available online: http://eur-lex.europa.eu/legal-content/EN/TXT/PDF/ ?uri=OJ:L:2015:068:FULL\&from=EN (accessed on 20 July 2015).

49. Arpaia, S.; Bartsch, D.; Delos, M.; Gathmann, A.; Hails, R.; Krogh, P.H.; Kiss, J.; Manachini, B.; Perry, J.; Sweet, J.; et al. European Food Safety Authority (EFSA) Panel on Genetically Modified Organisms (GMO Panel). Scientific Opinion on the assessment of potential impacts of genetically modified plants on non-target organisms. EFSA J. 2010, 8, 1-72.

50. Catacora-Vargas, G. Socio-economic considerations under the Cartagena Protocol on Biosafety: Insights for effective implementation. Asian Biotechnol. Dev. Rev. 2012, 14, 1-17.

51. Falck-Zepeda, J.B.; Zambrano, P. Socio-economic Considerations in Biosafety and Biotechnology Decision Making: The Cartagena Protocol and National Biosafety Frameworks. Rev. Policy Res. 2011, 28, 171-195.

52. Kleinman, D.L.; Kinchy, A.J. Against the neoliberal steamroller? The Biosafety Protocol and the social regulation of agricultural biotechnologies. Agric. Hum. Values 2007, 24, 195-206. 
53. Stabinsky, D. Bringing social analysis into a multilateral environmental agreement: Social impact assessment and the biosafety protocol. J. Environ. Dev. 2000, 9, 260-283.

54. UN Meeting Agrees on Decisions to Advance the Implementation of the International Agreement on the Safe Use of Living Modified Organisms. Available online: http:/www.cbd.int/doc/press/ 2014/pr-2014-10-03-bscopmop7-en.pdf (accessed on 20 July 2015).

55. Friedmann, H. The political economy of food: The rise and fall of the postwar international food order. Am. J. Sociol. 1982, 88, 248-286.

56. Friedmann H.; McMichel, P. Agriculture and the state system: The rise and decline of national agriculture. Sociol. Ruralis 1989, 29, 93-117.

57. Goodman, D.E.; Redclift, M.R. From Peasant to Proletarian: Capitalist Development and Agrarian Transitions; Basil Blackwell: Oxford, UK, 1981.

58. Goodman, D.; Watts, M. Reconfiguring the rural or fording the divide?: Capitalist restructuring and the global agro-food system. J. Peasant Stud. 1994, 22, 1-49.

59. Dixon, J. A cultural economy model for studying food systems. Agric. Hum. Values 1999, 16, 151-160.

60. Marsden, T.K.; Arce, A. Constructing quality: Emerging food networks in the rural transition. Environ. Plann. A 1995, 27, 1261-1279.

61. Goodman, D.; DuPuis, E.M. Knowing food and growing food: Beyond the production-consumption debate in the sociology of agriculture. Sociol. Ruralis 2002, 42, 5-22.

62. Goodman, D. Food studies in the 'Age of Ecology': Nature, corporeality, bio-politics. Sociol. Ruralis 1999, 39, 17-38.

63. Winter, M. Geographies of food: Agro-food geographies - food, nature, farmers and agency. Prog. Hum. Geogr. 2005, 29, 609-617.

64. Beus, C.E.; Dunlap, R.E. Conventional versus alternative agriculture: The paradigmatic roots of the debate. Rural Sociol. 1990, 55, 590-616.

65. Murdoch, J.; Miele, M. "Back to nature": Changing "worlds of production" in the food sector. Sociol. Ruralis 1999, 30, 465-483.

66. Marsden, T.; Jo Banks, J.; Bristow, G. Food supply chain approaches: exploring their role in rural development. Sociol. Ruralis 2000, 40, 424-438.

67. Goodman, D.; DuPuis, E.M.; Goodman, M.K. Alternative Food Networks: Knowledge, Practice, and Politics; Routledge: Oxon, UK, 2012.

68. Holloway, L.; Kneafsey, M.; Venn, L.; Cox, R.; Dowler, E.; Tuomainen, H. Possible food economies: A methodological framework for exploring food production-consumption relationships. Sociol. Ruralis 2007, 47, 1-19.

69. Constance, D.; Friedland, W.H.; Renard, M.C.; Rivera-Ferre, M.G. The discourse on alternative agrifood movements. In Alternative Agrifood Movements: Patterns of Convergence and Divergence. Research in Rural Sociol. and Development; Constance, D.; Friedland, W.H.; Renard, M.C.; Rivera-Ferre, M.G. Eds.; Emerald Group Publishing Limited 21: Bingley, UK, 2014; Volume 21, pp. 3-46.

70. Allen, P.; FitzSimmons, M.; Goodman, M.; Warner, K. Shifting plates in the agrifood landscape: The tectonics of alternative agrifood initiatives in California. J. Rural Stud. 2003, 19, 61-75. 
71. DuPuis, E.M.; Goodman, D. Should we go "home" to eat: Toward a reflexive politics of localism. J. Rural Stud. 2005, 21, 359-371.

72. Feagan, R. The place of food: Mapping out the 'local' in local food systems. Prog. Hum. Geogr. 2007, 31, 23-42.

73. Hines, C. Time to replace globalization with localization. Global. Environ. Politics. 2003, 3, 1-7.

74. Hinrichs, C. The practice and politics of food system localization. J. Rural Stud. 2003, 19, 33-45.

75. Kloppenburg Jr.; Hendrickson, J.; Stevenson, G.W. Coming in to the foodshed. Agric. Hum. Values 1996, 13, 33-42.

76. Marsden, T. The quest for ecological modernisation: Re-spacing rural development and agri-food studies. Sociol. Ruralis. 2004, 44, 129-146.

77. Mount, P. Growing local food: Scale and local food systems governance. Agric. Hum. Values 2012, 29, 107-121.

78. Renting, H.; Marsden, T.K; Banks, J. Understanding alternative food networks: Exploring the role of short food supply chains in rural development. Environ. Plann. A 2003, 35, 393-412.

79. Seyfang, G. Ecological citizenship and sustainable consumption: Examining local organic food networks. J. Rural. Stud. 2006, 22, 383-395.

80. Sonnino, R. Embeddedness in action: Saffron and the making of the local in southern Tuscany. Agric. Hum. Values 2007, 24, 61-74.

81. Watts, D.C.H.; Ilbery, B.; Maye, D. Making reconnections in agro-food geography: Alternative systems of food provision. Prog. Hum. Geogr. 2005, 29, 22-40.

82. Wilkins, J.L. Eating right here: Moving from consumer to food citizen. Agric. Hum. Values 2005, 22, 269-273.

83. Guthman, J. The trouble with 'organic lite' in California: A rejoinder to the 'conventionalisation' debate. Sociol. Ruralis. 2004, 44, 301-316.

84. Roff, R.J. No alternative? The politics and history of non-GMO certification. Agric. Hum. Values 2009, 26, 351-63.

85. Guthman, J. Neoliberalism and the making of food politics in California. Geoforum 2008, 39, 1171-1183.

86. Parkins, W.; Craig, G. Culture and the politics of alternative food networks. Food Culture Soc. 2009, 12, 77-103.

87. Robin, J.R. Shopping for change? Neoliberalizing activism and the limits to eating non-GMO. Agric. Hum. Values 2007, 24, 511-522.

88. Sonnino, R.; Marsden, T. Beyond the divide: Rethinking relationships between alternative and conventional food networks in Europe. J. Econ. Geogr. 2006, 6, 181-199.

89. Jaffee, D.; Howard, P.H. Corporate cooptation of organic and fair trade standards. Agric. Hum. Values 2010, 27, 387-399.

90. Renting, H. Special issue: Civic food networks. Int. J. Sociol. Agric. Food 2012, 19, 289-464.

91. Wilson, A. Beyond alternative: Exploring the potential for autonomous food spaces. Antipode 2013, 45, 719-737.

92. Sonnino, R.; Marsden, T.K. Alternative food networks in the south west of England: Towards a new agrarian eco-economy? In Research in Rural Socioogy and Development; Marsden, T., Murdoch, J., Eds.; Emerald Group Publishing Limited: Bradford, UK, 2005; p. 299. 
93. Lockie, S.; Halpin, D. The 'conventionalisation' thesis reconsidered: Structural and ideological transformation of Australian organic agriculture. Sociol. Ruralis 2005, 45, 284-307.

94. Marsden, T.K. Agri-food contestations in rural space: GM in its regulatory context. Geoforum 2008, 39, 191-203.

95. Freyer, B.; Bingen, J. Organic and non-organic farming: Is convergence possible? In Alternative Agrifood Movements: Patterns of Convergence and Divergence. Research in Rural Sociology and Development; Constance; D., Renard, M., Rivera-Ferre, M., Eds.; Emerald Group Publishing Limited: Bingley, UK, 2014; pp. 281-310.

96. Arce, A.; Marsden, T.K. The social construction of international food: A new research agenda. Econ. Geogr. 1993, 69, 293-311.

97. Busch, L.; Juska, A. Beyond political economy: Actor networks and the globalization of agriculture. Rev. Int. Polit. Econ. 1997, 4, 688-708.

98. Goodman, D. Ontology matters: The relational materiality of nature and agro-food studies. Sociol. Ruralis 2001, 41, 182-200.

99. Jarosz, L. Understanding agri-food networks as social relations. Agric. Hum. Values 2000, 17, 279283.

100. Lockie, S.; Kitto, S. Beyond the farm gate: Production-consumption networks and agri-food research. Sociol. Ruralis. 2000, 40, 3-19.

101. Lockie, S. Networks of agri-environmental action: Temporality, spatiality and identity in agricultural environments. Sociol. Ruralis. 2006, 46, 22-39.

102. Roe, E.J. Things becoming food and the embodied, material practices of an organic food consumer. Sociol. Ruralis 2006, 46, 104-21.

103. Callon, M.; Law, J. On the construction of sociotechnical networks: Content and context revisited. Knowl. Soc. 1989, 8, 57-83.

104. Law, J.; Mol, A. The actor-enacted: Cumbrian sheep in 2001. In Material Agency: Towards a Non-anthropocentric Approach; Springer Science: New York, NY, USA, 2008; pp. 57-77.

105. Murdoch, J. Inhuman/nonhuman/human: Actor/network theory and the prospects for a nondualistic and symmetrical perspective on nature and society. Environ. Plan. D 1997, 15, 731-756.

106. Harvey, M.; Quilley, S.; Beynon, H. Exploring the Tomato: Transformations of Nature; Economy and Society. Edward Elgar: Cheltenham, UK, 2002.

107. Tsing, A. Frictions: An Ethnography of Global Connections; Princeton University Press: Princeton, NJ, USA, 2012.

108. Venturini, T. Diving in magma: How to explore controversies with actor-network theory. Public Underst. Sci. 2010, 19, 258-273.

109. Tironi, M.; Salazar, M.; Valenzuela, D. Resisting and accepting: Farmers' hybrid epistemologies in the GMO controversy in Chile. Technol. Soc. 2013, 35, 93-104.

110. Veltri, G.; Suerdem, A.K. Worldviews and discursive construction of GMO-related risk perceptions in Turkey. Public Underst. Sci. 2013, 22, 137-154.

111. Marcus, G. Ethnography in/of the world system: The emergence of multi-sited ethnography. Annu. Rev. Anthropol. 1995, 24, 95-117.

112. Hannerz, U. Transnational Connections: Culture, People, Places; Psychology Press: London, UK, 1996. 
113. Hannerz, U. Being there... and there... and there! Reflections on multi-site ethnography. Ethnography 2003, 4, 201-216.

114. Burawoy, M. Revisits: An outline of a theory of reflexive ethnography. Am. Socioll. Rev. 2003, 68, 645-79.

115. Wittel, A. Ethnography on the move: From field to net to internet. Qual. Soc. Res. 2000, 1, 1-9.

116. Horst, C. Expanding sites: The question of depth explored. In Multi-Sited Ethnography: Theory, Praxis and Locality in Contemporary Research; Ashgate: Burlington, NJ, USA, 2009; pp. 119-135.

117. Benson, P.; Fischer, E.F. Broccoli and desire. Antipode 2007, 39, 800-820.

118. Cook, I. Follow the thing: Papaya. Antipode 2004, 36, 642-664.

119. Cook, I.; Harrison, M. Follow the thing 'West Indian hot pepper sauce'. Space Cult. 2007, 10, 40-63.

120. Fausti, S.W. The causes and unintended consequences of a paradigm shift in corn production practices. Environ. Sci. Policy 2015, 52, 41-50.

121. James, C. Global status of commercialised biotech/GM crops. ISAAA Brief. 2013, 46, 1-20.

122. Wickson, F.; Wynne, B. The anglerfish deception: The light of proposed reform in the regulation of GM crops hides underlying problems in EU science and governance. EMBO Rep. 2012, 13, 100-105.

123. Dudek, C.M. GMO Food regulatory frameworks in the US and the EU. In The New and Changing Transatlanticism: Politics and Policy Perspectives; Routledge: New York, NY, USA, 2015; pp. 214-232.

124. Ruitenberg, C. Here be dragons: Exploring cartography in educational theory and research. Complicity 2007, 4, 7-24.

125. Venturini, T. Building on faults: How to represent controversies with digital methods. Public Underst. Sci. 2012, 21, 796-812.

126. Gaudenzi, S. The Living Documentary: From representing reality to co-creating reality in digital interactive documentary. Ph.D. Thesis, University of London, London, UK, 2013.

127. Grand, A.; Wilkinson, C.; Bultitude K.; Winfield, A.F.T. Open science: A new 'trust technology'? Sci. Commun. 2012, 34, 679-668.

128. Open Science-A Three Level Approach. Presentation at the Conference Science, Innovation and Society-Responsible Research and Innovation. Available online: http://alanwinfield.blogspot.no/ 2014/11/open-science-preaching-what-i-practice.html (accessed on 7 August 2015).

129. Paulston, R.; Liebman, M. An invitation to postmodern social cartography. Comp. Educ. Rev. 1994, 38, 215-232.

(C) 2015 by the authors; licensee MDPI, Basel, Switzerland. This article is an open access article distributed under the terms and conditions of the Creative Commons Attribution license (http://creativecommons.org/licenses/by/4.0/). 